\title{
A blueprint for bone health across the lifespan: engaging novel team members to influence fracture rates
}

\author{
S K Boyd, ${ }^{1}$ R E Rhodes, ${ }^{2} \mathrm{~J}$ Wharf Higgins, ${ }^{2}$ \\ H A McKay, ${ }^{3}$ K M Khan ${ }^{3}$
}

Physical activity is a key, and increasingly recognised lifestyle determinant of bone health. For the mildly sceptical reader, we remind you that $26 \%$ of adult bone mass is laid down in two growing years around puberty, ${ }^{1}$ resistance training mitigates a proportion of postmenopausal bone loss and Cochrane systematic reviews conclude that strength and balance training reduce falls by $35 \%$ (and thus, fall-related fractures) in older people. A 2008 BMJ cover article emphasised that preventing falls was key in the battle against fractures. The term, 'fallrelated' is a more accurate primary label than 'osteoporotic' for appendicular fractures among older people. And $80 \%$ of fractures occur in those who do not have osteoporosis. ${ }^{2}$

\section{POSITIVE NEXT STEPS - CROSSING DISCIPLINE BARRIERS}

Nihilism has no place when physical activity is a proven therapeutic agent. But there is also no point in adding to the long list of cross-sectional or athlete studies showing that exercise is associated with greater bone mass as measured by dual-energy x-ray absorptiometry (DXA). There are many great options and we admire the body of brilliant work in bone science and activity going on all over the globe. Here, we respectfully outline a few possible next steps in the spirit of sharing, capacity building and teamwork. Think Wikinomics rather than Moses' tablets.

\footnotetext{
${ }^{1}$ Schulich School of Engineering, University of Calgary, Calgary, Alberta, Canada

${ }^{2}$ School of Exercise Science, Physical and Health Education, University of Victoria, Victoria, British Columbia, Canada

${ }^{3}$ Centre for Hip Health and Mobility, University of British Columbia, Vancouver, British Columbia, Canada

Correspondence to K M Khan, Centre for Hip Health and Mobility, University of British Columbia, Vancouver, BC V6T 1Z3, Canada; karim.khan@ubc.ca
}

\section{BOTH RCTS AND COHORT STUDIES PROVIDE TREMENDOUS VALUE FOR SOCIETY}

There has been a rightful emphasis on randomised controlled trials (RCTs) (and systematic reviews) with the wisdom of evidence-based practice. It behooves us to recall that well-executed cohort studies complement RCTs. The Study of Osteoporotic Fractures and EPIDOS are just two of many wonderful bone cohort studies that point to mechanisms, address the inter-related determinants that are a factor of real life and provide a great opportunity for partners from various disciplines to come together.

\section{FOR BONE HEALTH, FOCUS ON SPECIFIC STAGES OF THE LIFESPAN}

Given that 12 months is a short time through the eyes of a bone, experts in bone health often focus on a window such as the very early years, the growing years, midlife or menopause. We see merit in this concentration and argue that advances in the applied science of bone health - changing fracture risk in the real world - will come with customised prescriptions tailored for various groups. Age and sex are just two 'segments' - other important differentiators will be race/ ethnicity, geography, educational/income background, etc. If a product as simple as Coke is sold to different customer segments in different ways around globe, why would a prescription for bone health come in a cookie-cutter format (to mix our nutrition analogies)?

\section{WHY DO BONES BREAK?}

This seems like it should be a simple question but just as 'what controls running speed' and 'why do muscles fatigue' remain unanswered, bone continues to protect its secrets. Advances in imaging that include peripheral quantitative CT (pQCT), highresolution $\mathrm{pQCT}$ and application of novel analysis methods including the finite element model are key to the future. Sport and exercise medicine researchers need to be teaming with investigators expert in these methods to make true advances. Examples of advances will include explaining the relative contribution of trabecular and cortical bone to fracture thresholds, and a better understanding of the role of cortical porosity. We need to learn how to use this knowledge effectively to not only better determine who may be at risk of fracture, but also to harness the visual aspect of these technologies to provide patient-specific feedback. Seeing is believing, and the impact of seeing an obviously weak bone may be enough to entice behavioural changes in a patient towards better bone health.

\section{WHY DON'T INDIVIDUALS ADOPT HEALTHY BEHAVIOURS?}

We aspire to 'Altius, Citius, Fortius' but execute 'Pepsius, Bigius Macius'. The discipline of psychology has provided a remarkable body of work on individuals' motivations and behaviours in experiments needed to control the external environment. Sociologists and others have proven that forces beyond the individual are critical too. Now is the time to marry those disciplines, mix in marketing expertise and see how a combination of influences can change human behaviour. That is a big challenge but so was travelling to the moon and unravelling the Human Genome. We can certainly begin with small steps and with respect to bone health, we need to explore the effects of providing people with appropriate physical environments, providing societal encouragements/incentives, promoting health literacy and self-efficacy, targeting specific personalities and bringing the power of media and advertising expertise to create 'sticky' messages that educate and resonate with different audiences. Some vision, a moderate budget - the right people in the room - very feasible.

\section{LOOK TO WIDER HORIZONS - FROM THE} INDIVIDUAL TO THE LARGE LEVERS

Human clinical bone research was largely influenced by orthopaedics and endocrinology, and the medical model that underpins those disciplines leads to 'patient-focus' - appropriate in the clinical care setting. However, from a public health perspective, it is incontrovertible that health is influenced by our experiences as a citizen in society, not just by 
individual risk factors and behaviours. Even when individuals know what they should be doing for 'bone health', it may well be that their circumstances prevent them from putting their knowledge into practice. A life marked by low income, poor self-esteem, stress and a sense of exclusion is not conducive to following the latest National Institutes of Health (NIH) or National Osteoporosis Foundation guidelines. Self-evident when pointed out, convenient to overlook, monumentally difficult to change without tending to the more upstream levers.

There is now a shift towards understanding the context within which people make lifestyle decisions so that we can create environments that support healthy choices. Also, we now know that peoples' life choices reflect their life's chances and circumstances. One respite for 'vulnerable' communities can be found in its social recreational activities yet this confluence - vulnerability and recreational opportunity - has been little investigated to date. There is a tsunami of power and potential that recreation and other community programmes have to nurture the health of citizens and their communities. Partnerships with local organisations such as Young Men's Christian Associations to name just one are likely to create healthy citizens and strong communities. We contend that the best research is augmenting individual models with social and environmental context. Thus, we strongly advocate for the fundamental power of the socioecological framework ${ }^{3}$ when considering diverse influences or choosing where to intervene.

\section{TIME TO INCLUDE RURAL AND REMOTE PARTICIPANTS IN NATIONAL RESEARCH STUDIES}

Researchers and funding agencies should embrace the technology that is a hallmark of our century - mobility both in vehicles and via remote data collection. National Health and Nutrition Examination Survey has been using 'data-trailers' to capture representative samples of the US population. Bone measurement instruments including DXA scanners and pQCTs can fit into mobile laboratories that can be driven using a regular license. It's time for health researchers to think like those pioneers who conceived the London Underground or the Sydney Harbour Bridge - take a Big Hairy Audacious Goal (BHAG) and make it happen with state of the art technology.

\section{MOVING FROM EFFICACY TO EFFECTIVENESS - TRANSLATION AND DISSEMINATION}

Funders appreciate the need for research that evaluates 'reach', real-life effectiveness (as distinct from laboratory efficacy) and also the cost of various initiatives. Thus, the best practice is often a promotional method that can maximise its reach, be effective in actually changing behaviour and cost less than other options. These are interactive components that need continual assessment as we translate research into action. The extremely effective intervention (in labbased research) that does not reach well and is costly will not translate well but neither will the high reach, low-cost but ineffectual (for behaviour change) intervention. Balance is key.

\section{IN THIS ISSUE!}

Speaking of having an impact on practice, this issues sees South Africa's iconoclast Professor Tim Noakes' analyse (see page 475) whether runners need to consider taking in 'salty' drinks to avoid hyponatraemia (clue, the answer is a resounding 'no'). From California, Dr Robert Sallis provides the text to underpin the message he has been taking around with world via Exercise is Medicine - physicians measure the variable that is the single biggest determinant of health and physical activity (see page 473). Australia's Professor Flicker takes up the battle to the NIH Consensus Group who underplayed the proven benefits of physical activity to prevent cognitive decline and dementia (see page 465). And from Copenhagen comes an important tool for measuring chronic groin pain that persistent bane among sports injuries (see page 478). As always, we encourage your discussion and contributions via the BJSM Blog (and Twitter@BJSM_BMJ!).

\section{Competing interests None.}

Provenance and peer review Commissioned; internally peer reviewed.

Br J Sports Med 2011;45:463-464. doi:10.1136/bjsports-2011-090054

\section{REFERENCES}

1. Bailey DA, McKay HA, Mirwald RL, et al. A six-year longitudinal study of the relationship of physical activity to bone mineral accrual in growing children: the university of Saskatchewan bone mineral accrual study. J Bone Miner Res 1999;14:1672-9.

2. Järvinen TL, Sievänen H, Khan KM, et al. Shifting the focus in fracture prevention from osteoporosis to falls. BMJ 2008;336:124-6.

3. Stokols D, Allen J, Bellingham RL. The social ecology of health promotion: implications for research and practice. Am J Health Promot 1996:10:247-51. 